* Doutorado em Direito pela Universidade Federal de Minas Gerais, Brasil (2007). Professor Adjunto II da Universidade Federal de Juiz de Fora, Brasil. E-mail: brunoalacerda@ig.com.br

** Graduando em Direito pela UFJF. Bolsista de Iniciação Científica - Programa de Apoio ao Recém-Doutor da Propesq-UFJF (2012-2013). E-mail: rafael.jcastro @ hotmail.com

\section{Entre ética e técnica: a pessoa e a racionalidade do direito}

\section{BETWEEN ETHICS AND TECHNICS: THE PERSON AND THE LEGAL RATIONALITY}

\author{
* Bruno Amaro Lacerda \\ ** Rafael Jose de Castro
}

Resumo: Na Modernidade, a razão técnica sobrepujou a razão ética e, com a pretensão de universalizar o saber e conferir-lhe cientificidade, transpôs o centro unificador do pensamento do plano metafísico para o plano lógico-instrumental. No campo da razão jurídica, essa mudança pôs à prova os fundamentos do Direito e os modos de sua compreensão e aplicação. Este artigo investiga se o Direito pode prescindir da razão ética ou se, ao contrário, ambas as racionalidades podem coexistir em torno de um mesmo propósito humano. Para tanto, elaboramos uma teoria da pessoa, na crença de que a questão só pode ser adequadamente resolvida a partir da dimensão constitutiva e suficiente do Direito.

Palavras-chave: Pessoa; Valor; Justiça; Razão.

\begin{abstract}
In modernity, the technical reason overcame the ethical reason, and, with the intention to universalize knowledge and make it scientific, changed the unifying center of thought of the metaphysical plane to the logical-instrumental plane. In the field of legal reason, this change threatened the foundations of Law and their understanding and application. This paper investigates whether the Law can dispense ethical reason or if, on the contrary, both rationalities can coexist around the same human purpose. To this end, we developed a theory of the person, in the belief that the question can only be adequately resolved through the constitutive and sufficient dimension of Law.
\end{abstract}

Keywords: Person; Value; Justice; Reason. 


\section{INTRODUÇÃO}

O avançar da técnica, no último século, trouxe elementos adicionais para os debates nas ciências humanas e sociais. E o Direito, que almeja regular a vida humana coexistencial, não ficou imune a isso. Por um lado, surgiram as agruras dos limites à liberdade humana no uso das novas tecnologias; por outro, os possíveis benefícios que algumas técnicas poderiam trazer para o Direito, especialmente em seu aspecto procedimental.

Mas também podemos indagar sobre as transformações do modo de pensar o Direito em uma sociedade marcada pelo primado da técnica. Há séculos afirma-se que sua função é a realização de um valor, a justiça, embora os juristas nem sempre tenham concordado sobre o seu significado. Valor elementar da convivência, a justiça foi (ou está sendo) afetada pela racionalidade técnica? Esta racionalidade convive ou pretende substituir a racionalidade ética na qual o Direito tradicionalmente se apoia? Estas são questões complexas, mas das quais não podemos nos esquivar. A busca por algumas respostas é o objetivo principal desta investigação.

\section{A PESSOA E A TÉCNICA}

Segundo Ortega y Gasset, a vida humana não é um mero produto da razão. Não se restringe à res cogitans cartesiana, pois viver é estar no mundo e com ele interagir constantemente. Isso não significa que o homem e o mundo perfaçam uma unicidade, já que é perfeitamente distinguível a presença do sujeito - a vida humana - daquela realidade que a ele se apresenta circunstancialmente. São, assim, dois extremos que se somam: o homem que vive e o mundo que o circunda. A realidade mundana surge como alheia ao próprio ser e a ele se revela como uma utilidade (um "ser para") ou dificuldade (um "ser contra"), pois, não sendo sujeito da vida humana, o mundo se põe como objeto desta.

A vida humana, em seu sentido biográfico, consiste em um processo de futurição, que transcende o momento presente e lança-se em direção ao futuro, pois "o que chamam de vida não é senão o afã de realizar um determinado projeto ou programa de existência” (ORTEGA Y GASSET, 1991, p. 30). Dessa forma, "a vida é futuriça, antecipação de si mesma a partir do presente e, portanto, primariamente é uma realidade imaginária, ou melhor, imaginativa" (MARÍAS, 1971, p. 214). Enquanto o mundo circunstancial (as coisas) se revela 
como algo estático por ter sua realidade prefixada e acabada, o homem é dotado de um núcleo pessoal. Diferentemente de sua circunstância, a realidade pessoal só é captada por um processo dinâmico: o homem é assim "um acontecimento dramático; um sujeito que é alguém que consiste em acontecer" (MARÍAS, 1996, p. 17). Por isso, toda pessoa traz consigo a insegurança de um "vir-a-ser" e, portanto, não se encerra em um ser imutável no tempo, mas em um "está sendo" sem nenhuma limitação apriorística. Em síntese, pode-se dizer que a pessoa é um constante processo de inovação, o ser capaz de criar seu próprio projeto de vida e de retificá-lo quando necessário.

Isso faz do homem um ser cuja realidade não coincide com sua potencialidade. Dito de outra maneira, o ser do homem não se encerra no presente, mas projeta-se sobre um "vir-a-ser" em potência - um "não-ser" ainda no presente. Diversamente, todo ente cuja realidade e potencialidade se confundem consiste em mera circunstância, porque tudo o que poderá ser está predeterminado naquilo que já é. É nesse sentido que o homem não pode ser reduzido à mera circunstância, pois esta presume a natureza objetiva, ao passo que o homem se revela sempre como uma pretensão de ser, autor de sua vida biográfica.

Ao homem "é dada a imperiosidade de ter de estar sempre fazendo algo, sob pena de sucumbir, mas não lhe é, de antemão e de uma vez para sempre, presente o que tem de fazer" (ORTEGA Y GASSET, 1960, p. 82). Ele precisa preencher sua vida com aquilo que escolhe para si do modo mais autêntico. Como seu ser se traduz sempre em possibilidade, então, para de fato "ser", precisará o homem "fazer". Neste sentido, deve necessariamente exercitar sua liberdade e guiar sua própria vida dentro de um universo de possibilidades. Ele está mesmo condenado a ser livre - sua vida é um processo de tomada de decisões no qual deverá lutar para fazer prevalecer seu projeto de vida sobre aquela circunstância que o envolve, resultando que "a liberdade não é qualidade inerente, mas tarefa por se realizar" (OLIVEIRA, 1993, p. 129).

Há, porém, um leque de situações não escolhidas - trata-se da própria circunstância - fatores que compõem o substrato material a partir do qual o homem forja suas possibilidades pessoais de associação imaginativa. São interferências alheias ao homem, chamadas por Ortega e Julián Marías de acaso.

Se o acaso aparece inicialmente como um fator de mitigação da liberdade pessoal, num segundo momento é exatamente o inverso que se verifica. Cada vida humana é capaz de captar e digerir biograficamente o mesmo evento 
casual de diferentes formas, e é a inserção desse evento em feixes diversos de possibilidades que lhe confere um caráter pessoal. Encontrar a conciliação entre o par acaso-necessidade é tarefa humana conferida à liberdade: assumir para si seu próprio destino é torná-lo autêntico, convertê-lo em dimensão pessoal da vida.

Pessoa e circunstância, portanto, têm de conviver constantemente, sem se confundirem nem se separarem. Embora não escolha sua circunstância, o homem nela se insere forçosamente, e diante dela deverá erigir seu projeto de vida e construir seu autêntico ser. A célebre expressão de Ortega "eu sou eu e minha circunstância" sintetiza esse processo.

Dela se extraem dois conceitos primários inseparáveis - o eu, homem que vive, e a circunstância, meio em que se vive. Supera-se o racionalismo cartesiano a partir do qual o homem é a res cogitans, única realidade primária, alheia ao mundo, bem como o empirismo aristotélico, segundo o qual o homem não passa de um pedaço do mundo, distinto dos demais seres pela razão. Homem e mundo são agora vistos como realidades igualmente primárias.

Disso decorre que o mundo é um conjunto de importâncias com as quais o indivíduo precisa lidar - seja porque lhe são úteis à realização de seu projeto, seja porque lhe opõem resistência ao imporem uma luta pela existência. A vida humana, ao contrário da circunstância, importa a si mesma: "é este para si mesmo (para o homem) o verdadeiro fim de todo projeto, e com maior razão do projeto de si próprio que o homem elabora" (COTTA, 1971, p. 131). A circunstância, por sua vez, nada mais é que o conjunto de objetos revelado à pessoa, e, por conseguinte, sua existência está condicionada à utilidade que assume para o homem. A importância das coisas é medida em função da pessoa e de seu projeto de vida, e não ao contrário.

Sua utilidade será aferida quando for capaz de suprir alguma demanda humana. A circunstância assumirá significado no momento em que for inserida nos desígnios do homem como parte do seu projeto de vida (COTTA, 1971, p. 95). Todas as necessidades humanas que derivam de sua natureza biológica se apresentam como condição indispensável para a existência e, assim, são de primeira ordem (ou necessidades naturais) - para serem satisfeitas, exigem um leque de ações primitivas. Por exemplo: se o homem sente fome, deve ingerir alimento e, se sente frio, se agasalhar. $\mathrm{O}$ surgimento de uma adversidade circunstancial que impeça a satisfação dessas necessidades impõe à pessoa o desencadear de um novo tipo de ação, capaz de produzir aquilo que não lhe foi dado de antemão. Ou seja, se sente fome, mas lhe falta o alimento, terá de 
cultivar, caçar e pescar. É fácil perceber que essas ações de segunda ordem "não são, pois, atos nos quais satisfazemos necessidades, mas atos que, de pronto, implicam o contrário: uma supressão daquele repertório primitivo de fazeres, pelo qual buscamos diretamente satisfazer necessidades" (ORTEGA Y GASSET, 1991, p. 9).

Enquanto os animais estão atados às suas necessidades vitais, o homem consegue desvincular-se momentaneamente dessas precisões para ocupar-se com ações que não se traduzem na satisfação de suas urgências vitais. Como toda a potencialidade animal é dada aprioristicamente pela sua realidade, sua existência não passa de um sistema de necessidades elementares associadas a um repertório de ações primitivas para sua satisfação. Dito de outra maneira, todo o seu ser coincide com a circunstância na qual se insere. Embora as mesmas demandas objetivas sejam sentidas pelo homem, ele não se encontra limitado a elas, de tal sorte que não as têm como parte de seu ser autêntico. O homem lida com sua circunstância, mas é algo radicalmente diverso dela. É por isso que Ortega o define como um "centauro ontológico, cuja metade está originalmente imersa na natureza, mas a outra metade transcende-a" (ORTEGA Y GASSET, 1991, p. 29).

É precisamente por não estar integralmente contido em sua circunstância que o homem é capaz de desvincular-se dela momentaneamente para ensimesmar-se, recolher-se em si mesmo e se ocupar com seu ser autêntico, ou seja, com a realização de seu projeto de vida. Essa fuga da circunstância permite que a pessoa elabore todo um repertório de ações de segunda ordem aptas a fornecer aquilo que não se encontra na natureza, permanente ou momentaneamente. Todos esses atos de segunda ordem possuem um denominador comum, "pressupõem e trazem em si a invenção de um procedimento" (ORTEGA Y GASSET, 1991, p.11) que amiúde resulta na produção de um artefato cujo funcionamento é suficiente para satisfazer a precisão natural. No limite, esses atos imprimem uma reforma da circunstância, realocando ou transformando seus recursos para criar o que nela antes não existia ou o que não se obteria espontaneamente.

O conjunto desses atos é a técnica, que Ortega define como "a reforma que o homem impõe à natureza em vista da satisfação de suas necessidades" (ORTEGA Y GASSET, 1991, p. 12). Percebe-se que a técnica não é, por si só, a satisfação das demandas elementares, mas a alteração da circunstância na qual a pessoa está inserida para, através dela, atingir a satisfação almejada. A técnica é a reação do homem à natureza primitiva que lhe é imposta a fim de 
forjar uma segunda natureza, desta vez artificial, "visto que é a adaptação do meio ao sujeito" (ORTEGA Y GASSET, 1991, p. 13), gerando uma circunstância mais favorável à permanência do homem no mundo. Os atos técnicos, na expressão heideggeriana, consistem na provocação da natureza, no sentido de chamá-la diante de nós (pro-vocá-la), "isto é, significa desvendar a natureza na sua essência" (COTTA, 1971, p. 49) para investigar seu âmago e, a partir dele, inovar não apenas quantitativamente, mas, sobretudo, qualitativamente. O esforço empregado na realização desses atos técnicos tem, portanto, o condão de criar novas possibilidades que não existiam naturalmente e, a partir delas, satisfazer as necessidades elementares com o mínimo esforço possível.

A técnica, deste modo, representa a pessoa em sua face mais autêntica, porque consiste em inovar, em um constante movimento criativo. Sendo a pessoa um ser futuriço, cuja realidade apresenta-se como um "vir-a-ser", toda relação estritamente pessoal nada mais é que um processo de autofabricação da vida humana, pelo qual a pessoa "está se fazendo" (MARÍAS, 1971, p. 36). Como o homem não tem seu ser dado naturalmente, seu projeto de vida não se realiza espontaneamente, obrigando-o a se por em movimento para se tornar completamente real. Ora, se a técnica é a fabricação daquilo que naturalmente não é dado, então o homem - por incompleto que seja - apresenta-se como um ser essencialmente técnico, pois sua vida se expressa sempre como um "vir-aser", um "que-fazer" de si próprio (MARÍAS, 1996, p. 17). Se a realidade humana apresenta-se como uma constante expansão, então a técnica é o meio pelo qual a pessoa se identifica autenticamente em seu ser. Ela é a ampliação da experiência humana e, por conseguinte, do próprio ser do homem, de tal sorte que "um homem sem técnica, ou seja, sem reação contra a natureza, não é um homem” (ORTEGA Y GASSET, 1991, p. 14).

\section{RAZÃO ÉTICA E RAZÃO TÉCNICA}

Nas sociedades pré-modernas, a capacidade de atuação do homem era vista de duas perspectivas distintas. Pela primeira, o fazer (téchne), o homem seguia as regras de adequação dos meios aos fins para produzir um objeto; pela segunda (práxis), buscava orientar eticamente sua conduta em face dos outros homens. Mas em ambas o limite da razão era dado pela natureza (physis), em cujas leis se buscava o parâmetro de ordem e perfeição para a vida humana. Técnica e ética possuíam, portanto, um fundamento comum.

A razão clássica, fundada nessa contemplação (theoría) da natureza, cedeu progressivamente espaço para o fazer produtivo (poíesis), deixando de 
se limitar pela ordem da natureza. Com a unificação de theoría e poíesis, a razão moderna conferiu "às racionalidades que dela procedem uma extraordinária eficácia como instrumento seja para a transformação da Natureza, seja para a transformação da Sociedade" (LIMA VAZ, 1995, p. 69). Assim, o cosmos deixou gradativamente de ser princípio de atuação para se converter em matériaprima a ser transformada.

Com o advento da Modernidade, o homem assume o papel de demiurgo, imbuindo-se da tarefa de governar todas as coisas e extrair do mundo os instrumentos para edificar seus propósitos (COTTA, 1971, p. 66). Pelo agir técnico, submete a natureza à sua vontade, pondo-se no papel de centro do cosmos, enquanto "o mundo lhe aparece, portanto, em primeiro lugar, como material a ser transformado pela subjetividade, em vista de sua auto-realização" (OLIVEIRA, 1993, p. 123).

A razão moderna, essencialmente técnica, desperta com a ideia de que o homem deve dominar completamente a natureza: "Deste então, 'boas' serão todas aquelas ações que libertam o homem da sua impotência em relação à natureza" (GALIMBERTI, 2006, p. 522-523). Por conseguinte, o agir ético é dominado pelo agir técnico, não apenas porque os fins deste são vistos como bons, mas principalmente porque "criando um mundo menos natural e cada vez mais artificial, a técnica obriga a ética a perseguir a paisagem que a técnica produz e não cessa de transformar", eclipsando quaisquer outros referenciais que não aqueles por ela produzidos.

Ao submeter a ética, não tardou para que a técnica se tornasse autônoma e alheia a qualquer agir finalístico. Assim, “o fazer superou em muito o agir, e essa é a razão pela qual a ética, que domina o agir, não é capaz de regular a técnica, da qual procede o fazer" (GALIMBERTI, 2006, p. 523). A insuficiência contemporânea da ética decorre, portanto, da incapacidade de suas normas preverem e avaliarem todas as possibilidades despertadas pelas novas técnicas. Ademais, ao enxergar a técnica como a via exclusiva para a satisfação de seu bem-estar, o homem acabou por confundir meios e fins, vendo a técnica não mais como o meio pelo qual concretizaria seu projeto de vida, mas como o próprio projeto. Como consequência, fez de si mesmo um mero produto de sua técnica, abrindo perigoso caminho para sua própria reificação.

Se, para a razão ética, todo o saber deve ser direcionado ao bem (o aprimoramento moral do homem), para a razão técnica o conhecimento é convertido em poder e elevado à categoria de fim em si mesmo. Com essa preponderância, "a razão ética é deslocada progressivamente para o âmbito da 
subjetividade, da crença individual e substituída pela razão objetiva do conhecimento técnico" (ROBLES, 2005, p. 70). Não há mais espaço para o pensamento metafísico, do qual se extraía a universalidade da ética, restandolhe tão-somente um plano residual, relegado à consciência e à interioridade.

Essa supremacia da razão técnica impôs uma reforma à razão ética pelo "deslocamento do centro unificador das racionalidades do polo metafísico para o polo lógico" (LIMA VAZ, 1995, p. 70), que terminou por dispersar as diversas formas de racionalidade. Junte-se a esse quadro o fato de que, após a II Guerra Mundial, a razão técnica assumiu dimensões antes inimagináveis e tudo passou a ser pensado a partir do primado tecnológico, inclusive as próprias relações interpessoais. Nesse contexto situa-se o problema mais específico que queremos abordar.

\section{O DIREITO ENTRE RAZÃO TÉCNICA E RAZÃO ÉTICA}

O Direito tem por propósito permitir a realização do projeto humano pela harmonização das liberdades. Para tanto, é construído como um sistema normativo que postula padrões de conduta e métodos de resolução de conflitos, regulando o encontro intersubjetivo de seus agentes. Isso denota, segundo António Castanheira Neves, o caráter deontológico da racionalidade jurídica, que só se manifesta verdadeiramente no momento em que os homens se reconhecem reciprocamente como sujeitos (CASTANHEIRA NEVES, 2002, p. 861). O homem não reconhecido como sujeito de direito torna-se mero objeto e passa a servir aos desígnios dos demais homens que com ele se relacionam. O senhor reconhece no escravo sua propriedade; as relações entre ambos exprimem o domínio material de um sobre o outro, não o reconhecimento intersubjetivo que se exige para o verdadeiro Direito.

Por isso, o pressuposto basilar da racionalidade jurídica é o homem como sujeito pessoal e ético. Dessa afirmação é possível extrair duas premissas fundamentais: liberdade e igualdade. A primeira é condição sine qua non para que se pense a normatividade, pois não há sentido em prescrever um dever-ser sem que a ele se contraponha um poder-ser diferente do prescrito (CASTANHEIRANEVES, 2002, p. 862). Ademais, a liberdade é um imperativo do próprio homem, pois, como dito, a vida humana não se encontra concebida de antemão, devendo ser construída pelas decisões tomadas pelo homem que busca realizar seu projeto de vida. É precisamente por ter de "fabricar-se" que, para o homem, a liberdade se revela como tarefa a ser concretizada. Daí a 
afirmação de que a aparição do homem no mundo "não é o aparecer de qualquer coisa, mas de alguém, que é ele mesmo um iniciador. É com a criação do homem que o princípio do começo veio ao mundo, o que evidentemente não é senão um modo de dizer que o princípio da liberdade foi criado ao mesmo tempo que o homem, não antes" (ARENDT, 2007, p. 193).

A liberdade faz do homem demiurgo de seu mundo, autor de sua vida biográfica, mas a presença de outros homens condiciona sua subjetividade. Quando o homem altera sua circunstância para realizar a si mesmo, está alterando o mundo ao seu redor e, por compartilhá-lo com as demais pessoas, também está produzindo alterações nas circunstâncias alheias, a partir das quais as demais subjetividades precisarão conviver. Por isso,

[...] o primeiro dever de toda liberdade é que ela se coloque limites; sem dúvida esta é a condição do seu existir. De fato, somente assim a sociedade se torna possível, sem a qual não pode existir o homem e nem mesmo seu domínio sobre a natureza. Quanto mais livre é a sociedade e quanto menos prejudicada pelo domínio do homem sobre o homem [...] tanto mais evidente e indispensável se torna, na relação interpessoal, o dever de limitação voluntária (JONAS, 1988, p. 30).

O homem, portanto, não é livre simplesmente quando faz o que quer, mas quando se torna responsável pelas relações com as outras pessoas, assumindo a tarefa da liberdade. Disso decorre o segundo princípio fundante do Direito, a igualdade. Para que as subjetividades voluntariamente limitem sua liberdade e viabilizem o diálogo intersubjetivo, precisam se reconhecer como iguais sujeitos de direito. Note-se que "a individualidade humana não nos impõe a pessoa, para acendermos da individualidade à pessoa temos que passar do plano simplesmente antropológico para o mundo da coexistência ética" (CASTANHEIRA NEVES, 2002, p. 863). A pessoa não é meramente uma categoria ontológica, mas uma categoria axiológica: sua existência no mundo não deriva de um fenômeno natural, mas do reconhecimento no âmbito da coexistência das subjetividades. O reconhecimento da pessoa deriva do diálogo entre as liberdades; por isso se diz que este reconhecimento deve ser recíproco. Não basta que o escravo reconheça a personalidade de seu senhor se este não lhe retribui de igual forma. A reciprocidade torna evidente a natureza intersubjetiva do humano e traz à baila o princípio da ética igualação do homem: "como pessoas, todos os homens são iguais" (CASTANHEIRA NEVES, 2002, p. 867). 
A intersubjetividade exprime a condição social do homem, sobre a qual se apoia o Direito. O binômio de exigibilidade recíproca "direito e dever", por exemplo, nada mais é que a tradução jurídica do "eu e o outro". Diante disso, a institucionalização das relações intersubjetivas, embora seja uma condição necessária para o surgimento do Direito, não é sua condição suficiente, como adverte Castanheira Neves. Basta avaliar a possibilidade de se emergir uma ordem social normativa que garanta um sistema escravagista ou totalitário, ou qualquer outro que resulte na reificação do homem e na conversão das relações pessoais em mera sujeição. Por isso, "não é assim o direito uma qualquer institucionalização, mas uma institucionalização de uma certa índole, a exigir por essa sua índole específica uma outra condição para sua emergência e constituição como direito" (CASTANHEIRA NEVES, 2002, p. 861). Portanto, é imprescindível para uma ordem normativa a incorporação da condição ética.

Tradicionalmente, a ciência jurídica sempre foi alocada como um saber prático (práxis), por pretender orientar o agir humano na persecução de decisões mais justas e corretas. No entanto, a racionalidade jurídica não está imune aos influxos da técnica. No Direito, a presença da razão técnica se faz sentir hoje principalmente nos reclames por celeridade e na busca muitas vezes desordenada por uma maior decidibilidade dos conflitos. É certo que não devemos repugnar a celeridade, pois esta compõe a própria noção de justiça, como lecionou Chiovenda (apud GRECO, 2012, p. 274). Além disso, o fator tempo assumiu papel central nas relações humanas, de tal modo que a resposta às demandas postuladas perante o Poder Judiciário não pode se protrair indefinidamente, sob pena de não ser mais efetiva às partes. Cabe-nos, contudo, pensar a questão em todas as suas implicações.

Ao favorecer o avanço tecnológico, a razão técnica remodelou as relações interpessoais, resultando em um vultoso aumento de processos judiciais e no nascimento de novos ramos autônomos no Direito. Como exemplo, a intensificação das relações de consumo e o que se convencionou chamar de "sociedade de massas" impôs a formação do microssistema jurídico do direito do consumidor. De modo similar, a preocupação com questões de ordem ambiental exigiu das legislações um tratamento específico que antes não existia.

A soma da ineficiência do Poder Público em efetivar os direitos tradicionais com o surgimento dos "novos direitos" explica em parte o crescimento vertiginoso de ações ajuizadas perante o Judiciário. Esse acúmulo de processos - muitos dos quais exigem uma expertise que foge aos magistrados - afeta diretamente a tempestividade das decisões, terminando por gerar certo descrédito entre os jurisdicionados. Segundo relatório do Conselho Nacional de 
Justiça, o déficit de produtividade é o principal fator que contribui para o abarrotamento do sistema. Em 2011 foram 18.526 milhões de novas ações no Brasil, número este que subiu para 20.575 milhões no ano seguinte, um crescimento de $11,06 \%$. Em contraste, o número de decisões prolatadas cresceu, no mesmo período, de 17.054 milhões para 18.528 milhões, representando um aumento de $8,69 \%$.

A reação natural a esse problema passou pela simplificação dos procedimentos e pela criação de novos institutos jurídicos. Como exemplo, podemos citar as ações civis públicas, o rito sumaríssimo e a tutela antecipada no processo civil. Essas inovações, porém, não foram suficientes para fazer cessar as crescentes preocupações de produtividade. Em razão disso,

[...] na tentativa de debelar essa crise, os responsáveis pela administração da Justiça têm frequentemente recorrido a economistas e administradores, cuja visão desses problemas é puramente gerencial, resultado do que poderíamos chamar de análise econômica do processo, que passou a produzir dados e estatísticas de confiabilidade duvidosa e a propor metas quase exclusivamente quantitativas (GRECO, 2012, p. 278).

Isso revela um saber estritamente técnico, cuja finalidade maior é a produtividade dos juízes. Ocorre que nortear a racionalidade jurídica por parâmetros essencialmente técnicos pode distanciar o Direito de seu objetivo axiológico maior - a justiça - e convertê-lo em uma "máquina de decidibilidade". A esse propósito tem se rendido o ordenamento jurídico brasileiro. O inciso II do artigo $6^{\circ}$ da Resolução $n^{\circ} 106 / 10$ do Conselho Nacional de Justiça, por exemplo, ocupou-se com parâmetros de produtividade para aferição do merecimento dos magistrados de primeiro grau de jurisdição, quando de sua avaliação para promoção e acesso aos Tribunais de segundo grau. Elenca o dispositivo, in verbis:

Art. $6^{\circ} \mathrm{Na}$ avaliação da produtividade serão considerados os atos praticados pelo magistrado no exercício profissional, levando-se em conta os seguintes parâmetros:

II - Volume de produção, mensurado pelo:

a) número de audiências realizadas;

b) número de conciliações realizadas;

c) número de decisões interlocutórias proferidas;

d) número de sentenças proferidas, por classe processual e com priorização dos processos mais antigos; 
e) número de acórdãos e decisões proferidas em substituição ou auxílio no $2^{\circ}$ grau, bem como em Turmas Recursais dos Juizados Especiais Cíveis e Criminais;

f) o tempo médio do processo na Vara.

Nota-se que os critérios adotados pelo Conselho Nacional de Justiça para a promoção dos magistrados estão impregnados pela lógica da decidibilidade. Supervalorizam o volume de sentenças e alçam a produtividade e a celeridade ao status de valores-fins da racionalidade jurídica. A celeridade, como dito, é importante para a realização da justiça, mas é questionável que figure como a principal preocupação dos juízes.

A título de comparação, na segunda metade da década de 1980, o Trial Court Performance Standards (TCPS) estabeleceu padrões para aferir qualitativamente as decisões judiciais nos EUA, sendo seguido pela Comissão Europeia para Eficiência da Justiça (CEPEJ) em 2002. Os critérios listados pelo TCPS são agrupados em cinco categorias:

1. Acesso à justiça: elaboração de mecanismos que assegurem o acesso ao Judiciário por todos aqueles que dele necessitam;

2. Celeridade e tempestividade: o exercício da jurisdição deve ocorrer dentro de um período regular de tempo suficiente para a apreciação conclusiva da causa;

3. Igualdade e justiça: observância ao devido processo legal e aos julgamentos equânimes dos jurisdicionados;

4. Independência e controle: a responsabilidade legal, organizacional e de performance dos órgãos judiciários deve ser mensurada, monitorada e controlada publicamente;

5. Credibilidade e confiança: o trabalho do Judiciário deve sempre primar pela confiança e segurança dos jurisdicionados em relação às suas decisões (apud GRECO, 2012, p. 279).

Esses programas não negam a importância da celeridade, ao contrário, listam-na como requisito de qualidade do sistema. Apesar disso, também não se limitam a elevá-la ao patamar de único padrão para aferir a qualidade das decisões, importando-se também com a independência do Judiciário, a qualificação dos magistrados, a observância do devido processo legal e da igualdade, além de primarem pelo controle da administração da Justiça e pela responsabilidade dos agentes estatais que se desviam, por qualquer motivo, desses padrões. 
Isso mostra que o dilema entre celeridade e justiça é um falso dilema. Se não for posta em pauta a solução quantitativa dos processos, não se poderá falar em qualidade da jurisdição, mas, por outro lado, reduzir a qualidade à celeridade suprime o rol de valores caros ao Direito e o converte em mera técnica de decisão, pouco importando se justa ou não.

O sistema jurídico vai bem quando instrumentaliza as formas e institutos em prol da justa proteção da pessoa. Anda mal, porém, quando, sob pretexto de instrumentalizar os procedimentos, põe em risco garantias fundamentais no intuito exclusivo de atender à celeridade e otimizar a "produção" de sentenças. Este é o cenário desenhado pelo Conselho Nacional de Justiça, cujas metas são quase exclusivamente voltadas para a produtividade.

O risco é que o Direito se afaste de sua dimensão ética e deixe de se apresentar como verdadeira ordem. Afinal, quando se separa da ética, está, na verdade, abrindo mão da pessoa enquanto valor-fonte de sua possibilidade (CASTANHEIRA NEVES, 2002, p. 871). Assim reduzido, converte-se em mera tecnologia social de maximização da produtividade.

É crucial ter por norte a pessoa. Embora a técnica seja inerente à condição humana, o saber poiético está apto apenas para orientar sobre os meios para o alcance de um fim. Ele é capaz de fazer um juízo de adequação meio-fim, mas falha em estabelecer quais são esses fins (ROBLES, 2005, p. 64). Além disso, é incapaz de realizar um juízo valorativo sobre os fins eleitos, não podendo aferir a correção, a justiça ou a bondade destes. Sendo, por si só, uma racionalidade instrumental (um "saber para"), a razão técnica deve se manter fiel às categorias éticas e a serviço da pessoa. Somente assim logrará êxito em promover as relações intersubjetivas e se porá como um saber autenticamente humano.

Como explica Francesco D’Agostino (2010, p. 33), toda forma de saber é uma arte (uma techne), pois não existe uma forma lógica universal de saber. Nesse sentido, o saber jurídico também é uma forma de saber técnico do qual derivam algumas modalidades operativas. O problema começa quando o jurista atém-se exclusivamente a essas modalidades técnicas e se esquece dos valores aos quais sua técnica deve servir. Sem dúvida, o Direito exige procedimentos, sendo "correto, portanto, ressaltar o caráter essencialmente procedimental da experiência jurídica". O procedimento, porém, se guia por uma intencionalidade específica, a justiça: "Se se quer usar um paradigma conceitual diverso, se pode dizer que o procedimento jurídico deve manter sempre um referimento aos valores". E a justiça desemboca necessariamente em uma teoria da pessoa, 
pois o justo exige uma percepção da igualdade interpessoal que radica em um único princípio, o do reconhecimento: "Para o jurista, o princípio do reconhecimento converte-se no princípio constitutivo do direito (ou, se preferir, no seu pressuposto necessário), isto é, no princípio da igualdade" (D'AGOSTINO, 2010, p. 34).

A racionalidade técnica, portanto, não é suficiente para o Direito. $\mathrm{O}$ homem, o "centauro ontológico" de Ortega, é um ponto de tangência entre o natural e o moral, porque encerra em si, simultaneamente, o ser e o dever-ser. Nessa conexão entre o ontológio e o deontológico, o homem transcende sua natureza e emerge como o valor-fonte de todo o dever-ser: em sua dignidade, a pessoa humana é a razão pela qual e para a qual deve se orientar a razão jurídica. Como manifestação humana, o Direito não pode se despir de seus valores éticos, pois ao fazê-lo negará sua própria essência como ordem justa. Ao se deixar levar exclusivamente pela técnica desvia-se de seu objetivo e consagra os meios como fins, engessando as relações intersubjetivas e rompendo com sua fonte valorativa. Termina correndo o risco de instrumentalizar a pessoa e consagrar-se como sistema de institucionalização das relações de poder e dominação.

\section{CONSIDERAÇÕES FINAIS}

Aos poucos, a racionalidade técnica infiltrou-se em todos os campos do saber. Embora se possa afirmar que o homem é, por excelência, técnico - pois tem por tarefa construir sua própria vida biográfica - não se pode esquecer que o agir humano é também orientado para o aprimoramento moral de seu próprio ser. Sujeito de sua própria vida, o homem relaciona-se com o mundo objetivo que o circunda segundo uma lógica de dominação. Seus atos técnicos apresentam-se como uma reação à natureza, de modo que esta é transformada na busca pela concretização de seu projeto pessoal de vida. É nesse contexto que o homem se eleva à condição de demiurgo da sua circunstância e se percebe como sujeito livre, capaz de preencher sua vida de modo autêntico.

O aparecimento de outra subjetividade (o "outro"), no entanto, impede que as relações intersubjetivas possam ser reduzidas à mera dominação, afastando assim a incidência exclusiva da racionalidade técnica. A dimensão ética do homem confere-lhe uma condição pessoal e impede a reificação da sua subjetividade e da subjetividade dos demais homens, instaurando o diálogo e o reconhecimento (e não a dominação e a sujeição). 
A construção de um mundo autenticamente humano, que assegure as relações intersubjetivas, só é possível mediante um sistema normativo que prescreva condutas e solucione conflitos de forma justa: o Direito. A construção deste em prol da pessoa exige a racionalidade ética, parcialmente afastada pelo modelo de razão construído na Modernidade. Com as transformações trazidas pelo cientificismo, o Direito deixou-se influenciar pela lógica da produtividade, elevou a celeridade a valor-fim e passou a operacionalizar suas categorias como artefatos técnicos em busca de maior decidibilidade dos conflitos.

Embora o caráter técnico-procedimental seja inerente à experiência jurídica, o Direito só se sustenta como verdadeiro Direito quando ancorado na pessoa. Portanto, toda a técnica (da qual certamente o Direito pode se beneficiar) só encontra seu propósito quando destinada à persecução de um fim ético: a proteção integral da dimensão pessoal do homem. A isso devem estar atentos os juristas.

\section{REFERÊNCIAS}

ARENDT, Hannah. A Condição humana. 10. ed. Rio de Janeiro: Forense Universitária, 2007.

CASTANHEIRA NEVES, António. Coordenadas de uma reflexão sobre o problema universal do direito - ou as condições da emergência do direito como direito. In: ESTUDOS EM HOMENAGEM À PROFESSORA DOUTORA ISABEL DE MAGALHÃES COLLAÇO, 2., 2002, Coimbra. p. 837-871.

COTTA, Sergio. O desafio tecnológico. Coimbra: Arménio Amado, 1971.

D'AGOSTINO, Francesco. Di che cosa parliamo, quando parliamo di giustizia? In: . Valori giuridici fondamentali. Roma: Aracne, 2010. p. 27-38.

GALIMBERTI, Umberto. Psiche e Techne: o homem na idade da técnica. São Paulo: Paulus, 2006.

GRECO, Leonardo. Novas perspectivas da efetividade e do garantismo processual. In: MITIDIERO, Daniel; AMARAL, Guilherme Rizzo (Coord.). 
Processo Civil: estudos em homenagem ao professor Carlos Alberto Alvaro de Oliveira. São Paulo: Atlas, 2012. p. 273-308.

JONAS, Hans. Tecnica, libertà e dovere. Rivista di Teologia Morale, Bologna, v. 20, n. 77, p. 25-35, 1988.

LIMA VAZ, Henrique Cláudio de. Ética e razão moderna. Síntese, v. 22, n. 68, p. 53-85, 1995.

MARÍAS, Julián. Antropologia metafísica. São Paulo: Duas Cidades, 1971.

MARÍAS, Julián. Cara e Coroa da eletrônica. São Paulo: Companhia Editora Nacional, 1988.

MARÍAS, Julián. Persona. Madrid: Alianza, 1996.

OLIVEIRA, Manfredo Araújo de. Ética e racionalidade moderna. São Paulo: Loyola, 1993.

ORTEGA Y GASSET, José. Meditação sobre a técnica. Rio de Janeiro: Instituto Liberal, 1991.

ORTEGA Y GASSET, José. O homem e a gente. Rio de Janeiro: Livro Ibero-americano, 1960.

ROBLES, Gregorio. Os direitos fundamentais e a ética na sociedade atual. Barueri: Manole, 2005.

Submetido em: $21 / 09 / 2014$ Aprovado em: 23/11/2014

Como citar: LACERDA, Bruno Amaro; CASTRO, Rafael José de. Entre ética e técnica: a pessoa e a racionalidade do direito. Scientia Iuris, Londrina, v18, n.2, p.9-24, dez.2014.DOI:10.5433/2178-8189.2014v18n2p9. 